\title{
HIV/AIDS, a justiça e a busca por direitos
}

\author{
HIV/AIDS, justice and the search for rights \\ VIH/SIDA, justicia y búsqueda de derechos
}

Bruna Rafaela Dias Santos ${ }^{1 *}$, Marília Borborema Rodrigues Cerqueira ${ }^{1}$, Juliana de Melo Jorge ${ }^{1}$, Anne Lara Pereira Clementino ${ }^{1}$, Talita Gabriele Pereira Brito ${ }^{1}$, Rodolfo Ribeiro de Souza ${ }^{1}$, Leandro Luciano Silva Ravnjak', Maria Elizete Gonçalves'.

\section{RESUMO}

Objetivo: Refletir sobre a epidemia de HIV/AIDS, com enfoque em sua judicialização, por meio de análises dos Acórdãos do Tribunal de Justiça de Minas Gerais (TJMG), estudos doutrinários e legislativos, abordando os pontos históricos, jurídicos e os obstáculos que influíram na construção do direito à saúde, e óbices que incidem em sua judicialização. Métodos: Este trabalho caracteriza-se como um estudo exploratório e descritivo. As informações jurídicas foram coletadas de Acórdãos no site do TJMG, publicados entre 1/janeiro/2000 a 31/dezembro/2019, utilizando-se como critério de busca os termos "HIV" e "AIDS". Resultados: Foram encontrados e analisados 57 Acórdãos do TJMG, registrando-se que a busca por assistência farmacêutica e tratamento médico, seguida pelas ações de natureza cível para compensação por dano moral e para concessão de benefício previdenciário ou assistencial, respectivamente, ocupam o maior número de casos de judicialização da saúde dentro da epidemia. Conclusão: Concluiu-se que a construção do direito à saúde ocorreu em meio à epidemia do HIV/AIDS, sendo que o descaso com medidas de manutenção e custeio do sistema de saúde brasileiro, par a par com o desenvolvimento da epidemia, incidiu na frequente judicialização do sistema no Brasil.

Palavras-chave: HIV, Síndrome de imunodeficiência adquirida, Judicialização da saúde.

\begin{abstract}
Objective: Reflection about the epidemic of HIV/AIDS, with focus on its judicialization through Judgments analyses of the Justice Court of Minas Gerais (TJMG), doctrinal and legislative studies, alluding historical marks, juridical and obstacles that influenced on the construction in health's right and the hindrance that affect their judicialization. Methods: This work is characterized as an exploratory and descriptive study. The judicial information was collected in Judgments on TJMG website, published between January/1/2000 and December/30/2019, using as search criteria the terms "HIV" and "AIDS". Results: 57 Judgments of TJMG were found and analyzed, perceiving the search for pharmaceutical assistance and medical treatment, followed by civil actions for compensation for moral damage and granting social security or assistance benefit, respectively, occupy the largest number of cases of health's judicialization. Conclusion: It's concluded that the constriction of the health's right occurred in the middle of the HIVIAIDS epidemic. Being that the neglect of maintenance and costing measurements of the Brazilian health system, associated with the epidemic development, resulted in frequent judicialization of this system.
\end{abstract}

Key words: HIV, Acquired immunodeficiency syndrome, Health's judicialization.

\section{RESUMEN}

Objetivo: Reflexionar sobre la epidemia del VIH/SIDA, centrando se en su judicialización, a través del análisis de las decisiones del Tribunal de Justicia de Minas Gerais (TJMG), estudios doctrinales y legislativos, abordando los puntos históricos y jurídicos y los obstáculos que han influido en la construcción del derecho a la salud, y los obstáculos que afectan a su judicialización. Métodos: Se trata de un estudio exploratorio y descriptivo. La información jurídica se recopiló a partir de las sentencias publicadas en el sitio web del TJMG, entre el 1을 de enero de 2000 y el 31 de diciembre de 2019, utilizando como criterios de búsqueda los términos

${ }^{1}$ Universidade Estadual de Montes Claros (UNIMONTES), Montes Claros - MG.

*E-mail: brunadiassantosmg@gmail.com

SUBMETIDO EM: 1/2021

ACEITO EM: 1/2021

PUBLICADO EM: 2/2021 
"VIH" y "SIDA". Resultados: Se encontró y analizaron 57 sentencias judiciales del TJMG, registrando se que la búsqueda de asistencia farmacéutica y tratamiento médico, seguida de las acciones civiles de indemnización por daños morales y de concesión de prestaciones de seguridad social o asistenciales, respectivamente, ocupan el mayor número de casos de judicialización de la salud dentro de la epidemia. Conclusión: Se concluye que la construcción del derecho a la salud se produjo en medio de la epidemia de $\mathrm{VIH} / \mathrm{SIDA}$, y la negligencia con las medidas de mantenimiento y cálculo de costos del sistema de salud brasileño, junto con el desarrollo de la epidemia, se centro en la frecuente judicialización del sistema en el Brasil.

Palabras clave: VIH, Síndrome de inmunodeficiencia adquirida, Judicialización de la salud.

\section{INTRODUÇÃO}

No Brasil, a epidemia gerada pelo Vírus da Imunodeficiência Humana (HIV), causador da Síndrome da Imunodeficiência Humana (AIDS), reúne uma série de fatos, desde o protagonismo do modelo de resposta brasileira ao vírus, com tratamento 100\% gratuito pelo Sistema Único de Saúde (SUS); o desenvolvimento do arcabouço teórico de análise, expandindo os estudos para a área da vulnerabilidade e contemplando aspectos sociais e do contexto no qual o indivíduo vive até a busca por direitos, por meio da judicialização de questões diversas (CERQUEIRA MBR e RODRIGUES RN, 2016; SOUZA RR, et al., 2020).

A saúde é um direito fundamental que, além de propiciar o bem-estar da população, atribui ao Estado o dever em garanti-lo. A judicialização da saúde, por sua vez, é um meio utilizado pelos indivíduos para terem acesso à saúde por vias processuais (BARROSO LR, 2018). Diante disso, é oportuno analisar a construção do direito à saúde no Brasil, de acordo com os segmentos históricos e jurídicos e os obstáculos que influem em sua judicialização, com ênfase na epidemia de HIV/AIDS.

Retomando o Brasil colonial, o Estado não dispunha dos recursos necessários para cuidar da saúde da população, sendo que havia poucos profissionais de saúde e o acesso a eles era restrito. $O$ aparecimento de doenças contagiosas (epidemias e pandemias) favoreceu a criação da Junta de Higiene e Saúde Pública para controle dessas doenças (MENEGHEL SN, 2017).

No século XX, ganhou força a ideologia eugenista, influenciando os movimentos sanitaristas da época, que defendiam e impunham diversas reflexões acerca das mudanças e transformações na área da saúde, com enfoque na melhoria das condições de vida da população. Nessa perspectiva, deveria haver um controle científico das populações pertencentes às classes com baixas condições financeiras, os potenciais transmissores de doenças, e a promoção dos meios disponíveis para encorajar o crescimento das classes médias, os indivíduos saudáveis (FIUZA DH, 2016).

Após a Segunda Guerra Mundial, em 1948, houve a criação de um sistema jurídico internacional para a Proteção Internacional dos Direitos Humanos, constando direitos civis, políticos, econômicos, sociais e culturais (COMPARATO FK, 2007). Apesar de ser uma recomendação da Assembleia Geral das Nações Unidas, um dos seus principais órgãos da Organização das Nações Unidas (ONU), não possui força vinculante. Contudo, pelo costume e princípios jurídicos, esse Direito Internacional ganhou força imperativa, com natureza vinculante, na qual essas medidas passaram por um intenso processo de institucionalização pós Guerra Fria (PIOVESAN F, 2009; KLABBERS J, 2013).

Alguns anos após, durante a década de 1980, foram identificados, nos Estados Unidos, a infecção e o vírus causador do HIV/AIDS. No Brasil, o primeiro registro ocorreu em meados do ano de 1982, e os casos de HIV/AIDS passaram a ser associados especificamente aos "grupos de risco", principalmente, aos homossexuais, usuários de drogas injetáveis e prostitutas (BASTOS FI, 2006). Assim, houve a disseminação do vírus para pessoas que não faziam ou não se sentiam pertencentes dos grupos de risco, de modo a se qualificarem como não vulneráveis à infecção. Houve, também, um afrouxamento dos cuidados dessas pessoas, provocando o aumento do índice de infecções. Ao lado do referido cenário estigmatizante, houve 0 descaso dos agentes de saúde e, consequentemente, o HIV/AIDS passou a ser relacionado a comportamentos promíscuos e imorais (SAMPAIO LMS, 2018). 
Em meio ao espalhamento do HIV/AIDS, ocorreu a VIII Conferência Nacional de Saúde, em 1986, com a presença de profissionais da área da saúde, representantes de organizações e entidades e ampla participação da sociedade civil (ROSÁRIO CA, et al., 2020). Nesse encontro, houve um forte interesse pela ampliação do próprio conceito de saúde, e estabelecimento das diretrizes fundamentais para a construção do SUS, bem como foram debatidos os critérios para seu financiamento e organização do sistema. Além disso, foi criada a Comissão Nacional da Reforma Sanitária, cuja função era trabalhar na elaboração de um documento normativo para apresentação na Assembleia Nacional Constituinte.

Entretanto, somente com a Constituição Federal de 1988 (CF/88), o direito à saúde, tanto do ponto de vista jurídico como social, fixou-se como um direito de todos e dever do Estado, conforme preleciona o seu artigo 196. Igualmente, seguindo a mesma linha, o artigo 197 da CF/88 pressupõe que as ações e serviços de saúde são de relevância pública e é atribuído ao Poder Público o dever de assegurá-los, fiscalizá-los e regulamentá-los (BRASIL, 1988). Sendo assim, com a promulgação da CF/88, o Estado brasileiro assumiu o dever de atuar ativamente na promoção dos direitos sociais, incluindo o direito à saúde; ampliou também a legitimação no campo processual, o que, consequentemente, ocasionou um aumento no número de demandas e uma mudança nas relações estabelecidas entre a população e o Poder Judiciário, que começou a desempenhar um importante papel tanto do ponto de vista social, quanto político, para efetivação desses direitos (BARROSO LR, 2018).

Conforme dados divulgados pelo Ministério da Saúde (MS), no Boletim Epidemiológico da Secretaria de Vigilância em Saúde de 2019, foram diagnosticados 43.941 novos casos de HIV e 37.161 casos de AIDS no Brasil, em 2018 (BRASIL, 2019). Alguns estudos já alertavam para o recrudescimento da epidemia de HIV/AIDS no país, com tendência de crescimento da incidência de casos entre adolescentes, jovens e idosos (GRECO DB, 2016; CERQUEIRA MBR e RODRIGUES RN, 2016). Outro aspecto relevante é a perda da experiência brasileira de ação contra o vírus e a necessária lembrança de que essa luta deve ser intersetorial, sendo que todos os recursos possíveis devem ser mobilizados, novamente, para o controle da epidemia (SEFFNER F e PARKER R, 2016).

Nesse contexto, este artigo tem como objetivo refletir sobre a epidemia de HIV/AIDS, com enfoque em sua judicialização, por meio de análises dos Acórdãos do Tribunal de Justiça de Minas Gerais (TJMG), estudos doutrinários e legislativos, abordando os pontos históricos, jurídicos e os obstáculos que influíram na construção do direito à saúde, e óbices que incidem em sua judicialização.

\section{MÉTODOS}

Trata-se de estudo com abordagem qualitativa, baseado em pesquisa bibliográfica interdisciplinar, envolvendo a grande área do Direito e a grande área da Saúde; com o emprego da pesquisa documental, tendo como referencial a legislação pertinente à temática, e os julgados do Tribunal de Justiça do Estado de Minas Gerais (TJMG).

Foram coletados, na página oficial do TJMG, os Acórdãos para o presente estudo, por meio das ferramentas de busca do próprio portal e com a utilização das expressões de busca "HIV" e "AIDS", referentes ao período de 01/janeiro/2000 a 31/dezembro/2019. Os critérios de inclusão foram: o Acórdão deveria ter ambas as expressões de busca "HIV" e "AIDS"; o Acórdão deveria ser do período em estudo, de 1/janeiro/2000 a 31/dezembro/2019; o Acórdão deveria ser de domínio público. Como critério de exclusão, seria excluído o Acórdão que não cumprisse qualquer uma das exigências de inclusão. Os resultados apresentam os números absolutos e percentuais em relação aos totais. Quanto à metodologia de análise, optou-se pela análise de conteúdo, evoluindo para a hermenêutica dialética, reunindo os Acórdãos por temas afins na grande área do Direito (BARDIN L, 1979; MINAYO MCS, 2004; HABERMAS J, 1987).

Este estudo atende os preceitos éticos estabelecidos pela legislação que rege as pesquisas que envolvem seres humanos, Resolução CNS № 466, de 2012 e pela Resolução oㅜ 510, de 7 de abril de 2016, ambas do Ministério da Saúde. Visto que o material de estudo foi coletado na página oficial do TJMG, não foi necessária a aprovação por um Comitê de Ética em Pesquisa, pois os Acórdãos analisados são de domínio público. 


\section{RESULTADOS}

Na série temporal definida para a pesquisa, de 1 de janeiro de 2000 a 31 de dezembro de 2019, foram identificados 57 Acórdãos no TJMG e todos foram incluídos no estudo por atenderem os critérios de inclusão (Tabela 1).

Mais da metade, 57,89\% (33 Acórdãos) correspondem a demandas por medicamentos ou tratamento médico para as pessoas que vivem com HIV/AIDS, liderando em relação à judicialização da saúde no Estado de Minas Gerais. Em seguida, estão as ações de reparação civil por danos morais e, após, encontram-se diversos tipos de Acórdãos, todos relacionados ao HIV/AIDS.

Tabela 1 - Acórdãos do Tribunal de Justiça de Minas Gerais (TJMG), referentes às ações envolvendo HIV e AIDS, publicados entre 1/janeiro/2000 a 31/dezembro/2019.

\begin{tabular}{|c|c|c|}
\hline Variável & $\mathbf{N}$ & $\%$ \\
\hline \multicolumn{3}{|l|}{ Tipos de Ações } \\
\hline Demandas por medicamentos & 33 & 57,89 \\
\hline $\begin{array}{l}\text { Reparação civil por danos morais } \\
\text { em razão de 'falso-positivo' }\end{array}$ & 6 & 10,53 \\
\hline $\begin{array}{l}\text { Reparação civil por danos morais } \\
\text { em razão de divulgação indevida } \\
\text { de resultado }\end{array}$ & 4 & 7,02 \\
\hline $\begin{array}{l}\text { Reparação civil por danos morais } \\
\text { em razão de ofensa contra PVHA, } \\
\text { em razão de sua condição }\end{array}$ & 1 & 1,75 \\
\hline Demanda por transporte gratuito & 2 & 3,51 \\
\hline Demanda por pensão por morte & 3 & 5,27 \\
\hline Reforma em serviço militar & 2 & 3,51 \\
\hline $\begin{array}{l}\text { Aposentadoria por incapacidade } \\
\text { para o trabalho }\end{array}$ & 1 & 1,75 \\
\hline $\begin{array}{l}\text { Eliminação em concurso público, } \\
\text { em razão da condição de PVHA }\end{array}$ & 1 & 1,75 \\
\hline $\begin{array}{l}\text { Reconhecimento de entidade de } \\
\text { assistência social às PVHA }\end{array}$ & 1 & 1,75 \\
\hline Ações de natureza criminal & 3 & 5,27 \\
\hline Total & 57 & 100 \\
\hline
\end{tabular}

Legenda: PVHA = Pessoa que Vive com HIV/AIDS.

Fonte: Santos BRD, et al., 2020; dados extraídos do Tribunal de Justiça de Minas Gerais.

\section{DISCUSSÃO}

Pela análise dos julgados, verifica-se que demandas relativas à assistência farmacêutica lideram (em número absoluto e percentual) e observa-se que a Administração Pública é o recorrente mais frequente, alegando ilegitimidade passiva para a causa ou a ausência de recursos para prover o tratamento médico ao paciente, suscitando a solidariedade com os demais entes federados no que tange ao direito à saúde e sua efetividade.

Por outro lado, no polo ativo dessas ações figuram normalmente a própria pessoa que vive com HIV/AIDS, quando ocorre a negativa de determinado medicamento ou tratamento médico. Nesses pleitos, frequentemente, o autor solicita remédio ou tratamento não fornecido habitualmente pelo SUS e, para fazer jus a essa assistência específica, conforme a jurisprudência majoritária do Tribunal deve haver prova de que a medicação fornecida pelo SUS já não é mais eficaz para o tratamento do paciente e a probabilidade de resultados favoráveis a partir da adoção do método alternativo (TJMG, 2009).

Analisando-se os casos de judicialização da saúde, em especial no que tange a assistência farmacêutica, verifica-se ainda que a atuação de Organizações não Governamentais (ONGs) e da própria sociedade civil, teve grande relevância para que se firmasse, em todo o país, por meio de jurisprudências, um entendimento 
favorável à responsabilização dos entes federativos no cumprimento imediato da prestação estatal fundada no direito constitucional à saúde, que inclui o dever estatal de prestar assistência à saúde individual, de forma integral, universal e gratuita, pelo SUS (VENTURA M, et al., 2010).

Outro reflexo dos movimentos sociais pelo direito à saúde foi a promulgação da Lei 9.313/96, que estabeleceu o tratamento gratuito para as pessoas que vivem com HIV/AIDS, bem como o diagnóstico de HIV/AIDS por livre demanda, ou por necessidades específicas, sempre com o aconselhamento pré e pósteste, nas várias instâncias da rede de assistência do SUS. Para os indivíduos diagnosticados com o vírus, o atendimento se estrutura na atenção secundária e terciária do SUS, com centros de atendimento multiprofissionais especializados e hospitais. A atenção primária ainda possui pouca interferência nessa rede de atendimento, por várias questões que vão desde a falta de informação, estrutura, materiais e profissionais capacitados (FERREIRA DC e SILVA GA, 2012). Dados fornecidos pelo MS referentes aos óbitos por AIDS nos anos de 1996 e 2000 mostram o total de 9.600 mortos em 1996, e 1.200 mortos em 2000, revelando, portanto, a eficácia do tratamento (BRASIL, 2019).

Verifica-se, portanto, que o fenômeno da judicialização da saúde e a epidemia de HIV/AIDS guardam uma estreita relação, pois já nos anos 1980, quando ocorreu a identificação do novo vírus, os movimentos sanitaristas se organizavam para a criação de um sistema público de saúde, capaz de atender aos cidadãos de forma integral e universal (VENTURA M, et al., 2010).

No entanto, a trajetória para assegurar o direito à assistência farmacêutica no Brasil atingiu também importantes avanços por via da atuação do Poder Executivo e Legislativo, resultando em dois episódios marcantes: o primeiro ocorreu através de um ato executivo, quando pela primeira vez o Brasil adotou o licenciamento compulsório (ou "quebra de patente") do medicamento antirretroviral Efavirenz, visando estabelecer no Brasil um programa de produção local e distribuição gratuita, em observância ao disposto na Constituição (GRECO DB, 2016); o segundo, a partir da promulgação da Lei de Propriedade Industrial Brasileira (Lei $n^{\circ}$ 9.279/96), que admite o direito da produção do medicamento local em casos de utilidade pública ou quando o laboratório que detém a patente não o fabrica no país, conforme o artigo 71 dessa Lei (BRASIL, 1996).

Ainda a respeito do licenciamento compulsório, é importante salientar que conforme está disposto na CF/88, nos artigos 6ํㅜ e 196, o acesso à saúde está intimamente ligado à dignidade humana e deve ser efetivado em sua coletividade, sem distinção do poder econômico. Portanto, o tratamento do HIV/AIDS, no Brasil, deve estar ao acesso de todos, e as medidas referidas (licença compulsória) são uma forma de garantir que o governo cumpra o preceito constitucional. Ademais, ressalta-se que, apesar de a "quebra de patentes" ainda ser pouco utilizada, principalmente diante de todos os entreves políticos e econômicos que relacionam essa questão, trata-se de um modo possível para minimizar os impactos orçamentários ocasionados pela crescente judicialização da saúde (CARVALHO OF e SOUZA GA, 2020).

Em relação aos demais Acórdãos, foram encontrados 11 que tratam de ações de responsabilidade civil por danos morais, agrupados em três diferentes conjuntos: Acórdãos em decorrência de resultado equivocado de exame anti-HIV em exames de rotina; Acórdãos por divulgação indevida de resultado; e Acórdão por referência pejorativa ou comportamento discriminatório contra a pessoa que vive com HIV/AIDS.

De acordo com o Código Civil de 2002, nos artigos 186 e 927, aquele que por ação ou omissão voluntária, negligência ou imprudência, violar direito e causar dano a outrem, ainda que exclusivamente moral, comete ato ilícito fazendo nascer à responsabilidade civil, ou seja, dever de reparar o dano causado. A responsabilidade resulta da violação ao direito alheio e faz surgir para o agente causador do dano o dever de reparar a vítima, de modo a restabelecer, na medida do possível, o status quo ante (GONÇALVES CR, 2016).

A responsabilidade subjetiva é a regra no ordenamento jurídico brasileiro (PEREIRA CMS, 2018). Apesar disso, por força da teoria da responsabilidade objetiva, na primeira situação descrita, quando ocorre o resultado equivocado, que indica o estado sorológico positivo para HIV/AIDS, também chamado de 'falso positivo', conforme dispõe o artigo 14, caput, do Código de Defesa do Consumidor (CDC), a responsabilidade pelo dano causado é de natureza objetiva, uma vez que a atividade laboratorial exercida por entidade 
hospitalar ao paciente caracteriza-se como uma relação de consumo. Igualmente ocorre nos casos em que o Estado é responsável pelos danos decorrentes da prestação de um serviço público.

Dano moral é definido como aquele que atinge os direitos da personalidade, gerando ao lesado sentimento de dor, sofrimento ou tristeza. (GONÇALVES CR, 2016). Não compreende, portanto, a produção de efeitos patrimoniais, mas sim pressupõe que a vítima sofreu algum desgaste emocional diante da ocorrência do evento danoso. Sendo assim, tendo em vista o resultado 'falso-positivo' para HIVIAIDS, o contexto de discriminação e estigmatização contra as pessoas que vivem com o vírus, e o próprio temor do paciente diante do suposto quadro clínico, trata-se de uma hipótese passível de compensação em razão do dano moral enfrentado (TJMG, 2019). O dano moral deve ser contextualizado na persistente existência de preconceitos e estigmas no contexto da epidemia, mesmo após (quase) quatro décadas de luta e convivência com o vírus (GRECO DB, 2016).

Nos casos de divulgação indevida de exame, expondo o estado sorológico do paciente à terceiro, o entendimento do Tribunal é no sentido de que o prestador de serviços de saúde deve assegurar a preservação da integridade física e moral do paciente, inclusive quanto aos riscos do exame e a imprecisão do resultado, sob pena de responder pelos danos causados (TJMG, 2009a). Ademais, conforme a Lei no 12.984, de 2 de junho de 2014, que define o crime de discriminação contra a pessoa que vive com HIV/AIDS, artigo $1^{\circ}, \mathrm{V}$, divulgar a condição do paciente que vive com HIV/AIDS, com intuito de ofender-lhe a dignidade, é crime punível com reclusão de um a quatro anos e multa, ou seja, em tal hipótese, além dos efeitos cíveis, pode haver consequências criminais (BRASIL, 2014).

Tratando-se dos benefícios previdenciários e assistenciais (em sentido amplo), foram identificadas, ainda, ações por direitos como o transporte gratuito; ações referentes à reforma em serviços militar; ações pelo direito à pensão por morte em decorrência do vírus; e ação de aposentadoria por incapacidade laboral. Ressalte-se que a maioria das ações dessa natureza é movida contra o Instituto Nacional do Seguro Social (INSS), razão pela qual uma parcela considerável de processos previdenciários e assistenciais tramita na Justiça Federal, o que, inclusive, demanda outra análise para aprofundamento, a exemplo de um estudo dos acórdãos do Tribunal Regional Federal da Primeira Região.

O INSS guiou-se por muito tempo apenas pelas condições físicas da pessoa que vive com HIV/AIDS como fator norteador para a concessão de benefícios previdenciários e assistenciais. Dessa forma, aqueles que apresentavam a infecção em seu período assintomático tinham muitas vezes o seu direito negado. Esse entendimento desconsiderava que, além dos fatores físicos, as representações sociais do HIV/AIDS, os estigmas e preconceitos vivenciados pelas pessoas que vivem com HIV/AIDS, também atuam como limitadores para o exercício da atividade laboral, por exemplo. Diante da crescente judicialização de demandas dessa natureza, a 'teoria da incapacidade social', ou seja, aquela decorrente de condições pessoais e sociais foi recepcionada pela jurisprudência dos Tribunais brasileiros, como no caso do TJMG e, com o tempo, passou a ser aceita também na via administrativa, reduzindo-se o número de demandas judiciais (SOUZA RR, et al., 2020).

Por fim, têm-se os Acórdãos de natureza criminal; um Acórdão referente à eliminação injusta em seleção de concurso público, denotando todo o contexto de estigma e preconceito da epidemia; e um Acórdão referente ao reconhecimento de entidade de assistência social para pessoas que vivem com HIV/AIDS. No referido aspecto, vale lembrar a imprescindível luta intersetorial de combate à epidemia, com a soma de esforços com o objetivo de resgatar o protagonismo da resposta brasileira ao vírus.

\section{CONCLUSÃO}

Conclui-se, portanto, que o fenômeno da judicialização da saúde no Estado de Minas Gerais, no contexto do HIV/AIDS, representa prioritariamente a busca por assistência farmacêutica e tratamento médico; seguidas pelas ações de natureza cível, respectivamente, para compensação por dano moral e para concessão de benefício previdenciário ou assistencial, as quais ocupam o maior número de casos de judicialização da saúde. A partir da análise, é perceptível que as pessoas recorrem ao Poder Judiciário quando se sentem 
violadas, buscando a sua reparação por danos morais, seja por falso positivo ou pela divulgação indevida dos resultados ou por ofensa por ser uma pessoa vivendo com HIV/AIDS. Além disso, o judiciário é provocado quando há necessidade de tratamento farmacêutico e médico, através de benefícios previdenciários, uma vez que, como demonstrado, as representações sociais também atuam como limitadores aos direitos das pessoas que vivem com HIV/AIDS. Por fim, conclui-se que a Justiça, ao fazer valer o direito das pessoas que vivem com o vírus, tem importante papel no cerne da epidemia de HIV/AIDS no Brasil.

\section{AGRADECIMENTOS E FINANCIAMENTO}

Agradecemos ao Programa Institucional de Bolsas de Iniciação Cientifica (PROINIC) da Universidade Estadual de Montes Claros (UNIMONTES), bem como à Fundação de Amparo à Pesquisa do Estado de Minas Gerais (FAPEMIG) pela oportunidade e apoio financeiro, por meio de bolsa de IC.

\section{REFERÊNCIAS}

1. BARDIN L. Análise de Conteúdo. Lisboa: Ed. 70, 1979.

2. BARROSO LR. Curso de Direito Constitucional Contemporâneo: os conceitos fundamentais e a construção do novo modelo. 7. ed. São Paulo: Saraiva Educação, 2018.

3. BASTOS FI. Aids na terceira década. Rio de Janeiro: Editora FIOCRUZ, 2006.

4. BRASIL. 1988. In: Constituição da República Federativa do Brasil. Brasília/DF: Casa Civil, 1988.

5. BRASIL. 2019. Ministério da Saúde. Boletim Epidemiológico HIV/Aids. Brasília/DF: Ministério da Saúde, 2019.

6. BRASIL. Lei n. 10.406, 10 de janeiro de 2002. Institui o Código Civil. Diário Oficial da União, Brasília/DF, 2002.

7. BRASIL. Lei n. 9.279, de 14 de maio de 1996. Lei de Propriedade Industrial. Brasília/DF: 1996.

8. BRASIL. Lei № 12.984, 2 de junho de 2014. Define o crime de discriminação dos portadores do vírus da imunodeficiência humana (HIV) e doentes de AIDS.

9. CARVALHO OF, SOUZA GA. A desarmonia da judicialização das políticas públicas: reflexões críticas para a efetivação do direito à saúde no Brasil. Direitos Fundamentais \& Justiça, 2020; 14(42): 345-372.

10. CERQUEIRA MBR, RODRIGUES RN. Factors associated with the vulnerability of older people living with HIV/AIDS in Belo Horizonte (MG), Brazil. Ciência \& Saúde Coletiva, 2016; 21(11): 3331-3338.

11. COMPARATO FK. A afirmação histórica dos Direitos Humanos. 5. ed. São Paulo: Saraiva, 2007.

12. FERREIRA DC, SILVA GA. Caminhos do cuidado: itinerários de pessoas que convivem com HIV. Ciência Saúde Coletiva, 2012.

13. FIUZA DH. A Propaganda da Eugenia no Brasil: Renato Kehl e a implantação do racismo científico no Brasil a partir da obra "Lições de Eugenia". Rio Grande do Sul: Revista do Corpo Discente do PPG - História da UFRGS, 2016.

14. GONÇALVES CR. Direito Civil Brasileiro: Responsabilidade Civil. 11 ed., São Paulo: Saraiva, 2016.

15. GRECO DB. Trinta anos de enfrentamento à epidemia da Aids no Brasil, 1985-2015. Revista Ciência \& Saúde Coletiva [online], 2016; 21(5):1553-1564.

16. HABERMAS J. Dialética e Hermenêutica para a crítica da Hermenêutica de Gadamer. Tradução de Álvaro Vall. Porto Alegre: L\&PM, 1987.

17. KLABBERS J. International Law. Cambridge: Cambridge University Press, 2013.

18. MENEGHEL SN. Saúde e igualdade: a relevância do Sistema único de Saúde (SUS). Rio Grande do Sul: Cadernos IHU ideias, 2017.

19. MINAYO MCS. O Desafio do Conhecimento - pesquisa qualitativa em saúde. São Paulo: UCITEC Editora, 2004.

20. PEREIRA CMS. Responsabilidade Civil. Atual. Gustavo Tepedino. 12 ed., Rio de Janeiro: Editora Forense, 2018.

21. PIOVESAN F. Direitos Humanos e o Direito Constitucional Internacional. 10 ed., São Paulo: Saraiva, 2009.

22. ROSÁRIO CA, et. al. Sentidos da universalidade na VIII Conferência Nacional de Saúde: entre o conceito ampliado de saúde e a ampliação do acesso a serviços de saúde. Saúde em Debate, 2020; 44(124): 17-31.

23. SAMPAIO LMC. A Formação do Programa Nacional de DST/AIDS no Brasil. Instituto de Ciência Política - Unb, 2018.

24. SEFFNER F, PARKER R. Desperdício da experiência e precarização da vida: momento político contemporâneo da resposta brasileira à aids. Interface; Comunicação, Saúde, Educação, 2016; 20(57):293-304.

25. SOUZA RR, et al. Benefícios operacionalizados pelo INSS para a pessoa que vive com HIV/AIDS: judicialização e repercussão. In: Políticas públicas e suas especificidades, Rio de Janeiro: FGB / Pembroke Collins, 2020.

26. TJMG. Tribunal de Justiça de Minas Gerais. Apelação cível: 1.036.02.017150-4/001. Relator: Des. Generoso Filho. DJ: 17/03/2009. Portal TJMG, online, 2009a.

27. TJMG. Tribunal de Justiça de Minas Gerais. Apelação cível: 1.0702.14065209- 1/001. Relator: Des. Fernando Lins. DJ: 25/06/2019. Portal TJMG, online, 2019.

28. TJMG. Tribunal de Justiça de Minas Gerais. Mandado de Segurança: 1.0000.08.482381-4/000. Relator: Des. Armando Freire, DJ: 05/08/2009, Portal TJMG, online, 2009.

29. TJMG. Tribunal de Justiça de Minas Gerais. Pesquisa por Jurisprudência do TJMG. Acórdãos, 2020

30. VENTURA M, et al. Judicialização da saúde, acesso à justiça e a efetividade do direito à saúde. Physis: Revista de Saúde Coletiva, 2010; 20(1): 77-100. 